\title{
Highly Radiative Plasmas for Local Transport Studies and Power and Particle Handling in Reactor Regimes*
}

\author{
K.W. Hill, M.G. Bell, R.E. Bell, R. Budny, C.E. Bush, ${ }^{1}$ D.R. Ernst, \\ G.W. Hammet, D.R. Mikkelsen, H.K. Park, A.T. Ramsey, S.A. Sabbagh, ${ }^{2}$ \\ S.D. Scott, E.J. Synakowski, G. Taylor, and M.C. Zarnstorff \\ Princeton Plasma Physics Laboratory, Princeton University, Princeton, NJ 08543, USA \\ ${ }^{1}$ Oak Ridge National Laboratory, Oak Ridge, TN, USA \\ ${ }^{2}$ Columbia University, New York, NY
}

\begin{abstract}
To study the applicability of artificially enhanced impurity radiation for mitigation of the plasma-limiter interaction in reactor regimes, krypton and xenon gases were injected into TFTR supershots and high- $\mathrm{l}_{\mathrm{i}}$ plasmas. At neutral beam injection (NBI) powers $\mathrm{P}_{\mathrm{B}} \geq 30 \mathrm{MW}$, carbon influxes (blooms) were suppressed, leading to improved energy confinement and neutron production in both D and DT plasmas, and the highest DT fusion energy production (7.6 MJ) in a TFTR pulse. Comparisons of the measured radiated power profiles with predictions of the MIST impurity transport code have guided studies of highly-radiative plasmas in ITER. The response of the electron and ion temperatures to greatly increased radiative losses from the electrons was used to study thermal transport mechanisms.
\end{abstract}

*Work supported by U.S. Department of Energy, Contract No. DE-AC02-CHO-3073 


\section{INTRODUCTION}

In a tokamak reactor such as ITER more than $200 \mathrm{MW}$ of fusion alpha heating power must be dispersed. [1] Heat removal by radiation from controlled injection of impurity gases, either in the main chamber or in the divertor, is a promising technique for mitigating the severe problem of concentrated power loading of the divertor. [2] Experiments have shown that a large fraction of the heating power can be removed by impurity radiation without deleterious effects on plasma performance. [3,4] In TFTR [5], this technique has been extended to reactor regime plasmas $\left(\mathrm{T}_{\mathrm{e}}=5-9 \mathrm{keV}, \mathrm{T}_{\mathrm{i}}=20-40 \mathrm{keV}\right)$ and to higher- $\mathrm{Z}$ impurities, krypton and xenon, by injection of these gases [6] into supershot [7,8] and high internal inductance [9] plasmas. At the high electron temperatures in reactors, higher- $Z$ impurities are more appropriate because the lower- $Z$ impurities ionize to high charge states which produce little radiation. Furthermore, much lower concentrations of high- $Z$ ions can be used because of the very high specific radiation per ion $\left(\mathrm{P}_{\mathrm{rad}}\right.$ $\left.\sim \mathrm{Z}^{3}\right)$, resulting in lower fuel dilution $\left(\Delta \mathrm{n}_{\mathrm{H}} / \mathrm{n}_{\mathrm{e}} \sim<\mathrm{Z}>\mathrm{n}_{\mathrm{Z}} / \mathrm{n}_{\mathrm{e}}\right)$, where $\mathrm{n}_{\mathrm{H}}$ and $\mathrm{n}_{\mathrm{Z}}$, respectively, are the density of the hydrogenic fuel and impurity, and $\langle\mathrm{Z}>$ is the average charge state of the ions.

Two distinct experiments were performed in TFTR. These were (1) high neutral beam heating power $\left(\mathrm{P}_{\mathrm{b}} \geq 30 \mathrm{MW}\right)$ discharges for reduction of deleterious influxes of wall impurities (carbon "blooms") [10] and deuterium, and improved energy confinement and fusion power production; and (2) thermal transport studies at moderate power $\left(\mathrm{P}_{\mathrm{b}}=16 \mathrm{MW}\right)$.

These plasmas are distinctly different from the "Z-mode" of ISX-B [11] or "RI-mode" of TEXTOR [3] plasmas, which were performed at much lower temperatures and with lower-Z gases. The RI mode plasmas require injection of both neon and deuterium gas to achieve high density $\left(n_{e} \sim n_{e} G W\right.$, where $n_{e} G W$ is the Greenwald density [12]) and improved confinement (relative to L-mode), whereas in the TFTR experiments, high-Z gases were injected parasitically into steadystate supershots to reduce the power flow to the edge, and were not required for enhanced confinement.

\section{THERMAL TRANSPORT EXPERIMENTS}

The highly radiative plasmas provided a convenient tool for local transport studies, because the distribution of power loss between radiation and conduction plus convection was greatly changed (e. g., from $25: 75 \%$ to $75: 25 \%$ globally) in a locally measurable way, while the NB deposition profile was relatively unchanged. Krypton and xenon gases were puffed into TFTR supershots with $\mathrm{P}_{\mathrm{b}}=16 \mathrm{MW}$, a plasma current $\mathrm{I}_{\mathrm{p}}$ of $2 \mathrm{MA}$, and a toroidal magnetic field of $4.8 \mathrm{~T}$. Feedback control of the gas puff rate was used to maintain a constant radiated power fraction, $\mathrm{f}_{\mathrm{r}}=\mathrm{P}_{\mathrm{rad}} / \mathrm{P}_{\text {heat }}$, where $\mathrm{P}_{\mathrm{rad}}$ and $\mathrm{P}$ heat are the measured radiated power and neutral beam heating power. At radiated fractions as high as $80 \%$ the energy confinement time was not reduced. The electron temperature $\mathrm{T}_{\mathrm{e}}(\mathrm{r})$ was hardly changed, while the ion temperature $\mathrm{T}_{\mathrm{i}}(\mathrm{r})$ increased significantly in the radiative plasmas, by about $35 \%$ in the center and $10 \%$ near the edge.

Transport analysis for the Xe-puffing shot coupled the invariance of $\mathrm{T}_{\mathrm{e}}(\mathrm{r})$ to increased heating from ion-electron equipartition energy as both the electron density $n_{e}(r)$ and ion temperature $\mathrm{T}_{\mathrm{i}}(\mathrm{r})$ increased. The transport analysis indicated that $\chi_{\mathrm{e}}$ did not change in the core with the increased radiation from $\mathrm{Xe}$, while $\chi_{i}$ and $\chi_{\phi}$ decreased, as shown in Fig. 1 . The D $\alpha$ and CII line emission decreased by 40 and $15 \%$, respectively. The reduced D $\alpha$ emission would correlate with a confinement improvement of $10 \%$ under the normal supershot scaling. [13] 

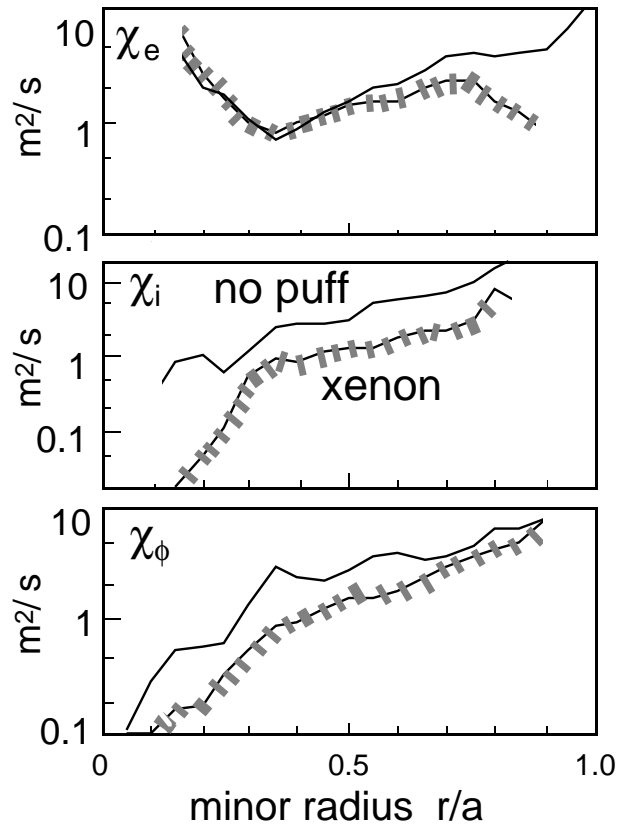

Fig. 1 Radial Profiles of the electron and ion thermal diffusivity and the momentum diffusivity with intrinsic ( $f=0.25$, solid curves) and xenonenhanced radiation ( $f r \approx 0.75$, dashed curves)

Improvements in energy confinement in tokamaks have recently been associated with the formation of flow shear layers which suppress the turbulence responsible for anomalous transport [14]. In this context, it should be noted that the poloidal velocity $v_{\theta}$ of carbon impurities about 15 $\mathrm{cm}$ inside the last closed flux surface increased from $1 \mathrm{~km} / \mathrm{s}$ to $5 \mathrm{~km} / \mathrm{s}$ just after the Xe puff. The poloidal rotation profile, expressed in terms of its contribution, $v_{\theta} B_{\phi}$, to the radial electric field $E_{r}$, is shown in Fig. 2a. Coupled with changes in the toroidal rotation, there is a factor of three increase in the total radial electric field $\mathrm{E}_{\mathrm{r}}$ to $\sim 50 \mathrm{kV} / \mathrm{m}$ at this location. The evolution of the components of the equilibrium radial field $E_{\mathrm{r}}$ at the radius of its maximum excursion are shown in Fig. 2b. Changes in $E_{r}$ of similar magnitude have been associated with the formation of transport barriers in TFTR ERS plasmas [15].

\section{POWER AND PARTICLE HANDLING}

At heating powers above $30 \mathrm{MW}$ in TFTR, the fusion neutron production and energy confinement time were often limited by large influxes of carbon and hydrogenic species from the limiter. The radiative-regime experiments successfully suppressed the carbon "blooms" by reducing the power flowing to the edge. These experiments were done at $I_{p}=2.2-2.6 \mathrm{MA}$ and $\mathrm{B}_{\mathrm{T}}=5.1-5.5 \mathrm{~T}$. In D plasmas with $\mathrm{P}_{\mathrm{B}} \geq 30 \mathrm{MW}$, increasing the radiated power fraction from the normal $\sim 25 \%$ to levels of $45-70 \%$ by injection of either $\mathrm{Kr}$ or Xe suppressed carbon blooms and
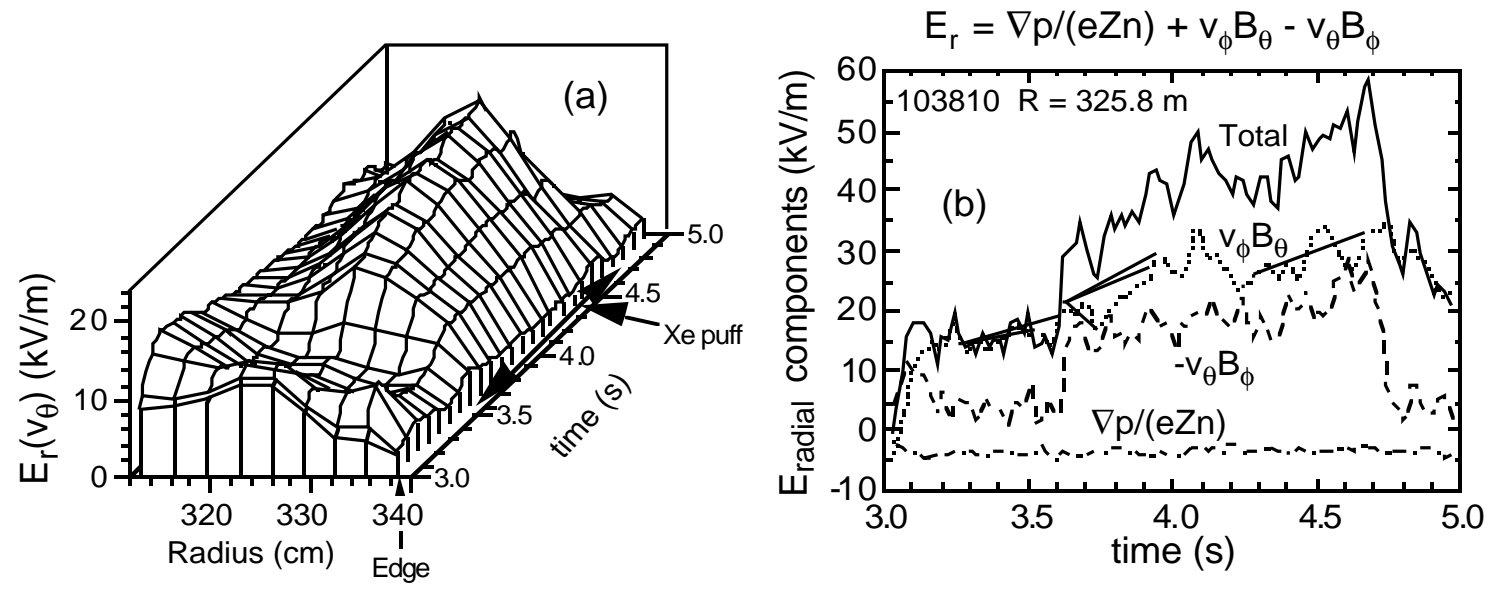

Fig. 2 (a) Radial electric field $E_{r}$ resulting from the poloidal velocity $v_{\theta}$, showing peaking during Xe puff. (b) E $E_{r}$ components and total $E_{r}$ at the location of peaking in (a). 


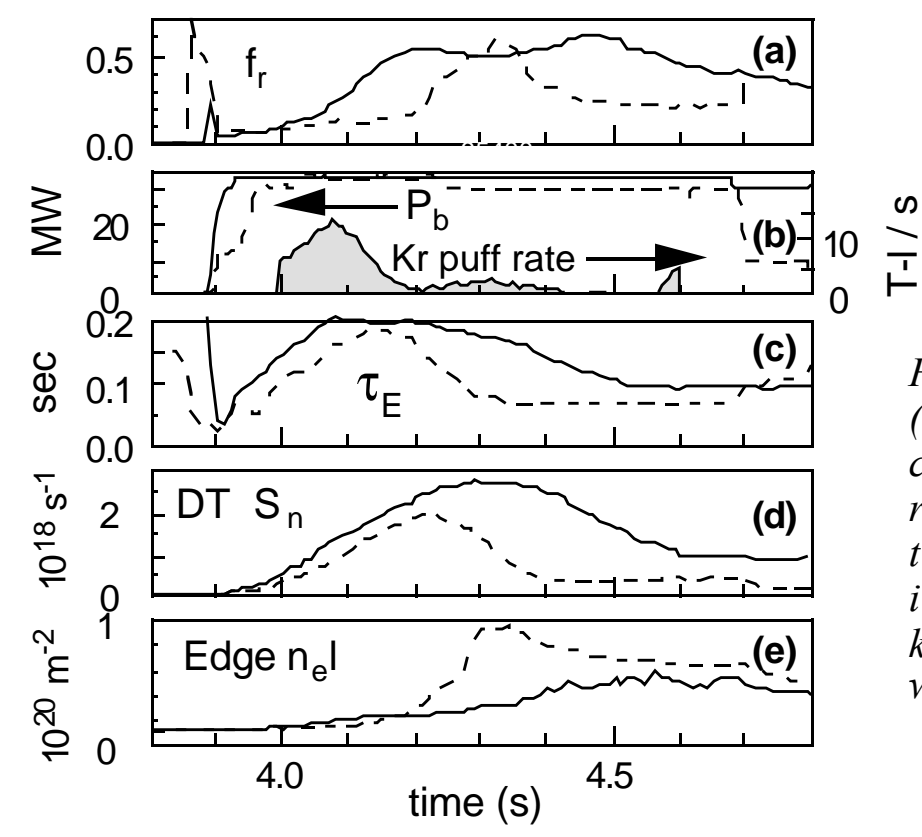

Fig. 3 (a) Radiated power fraction, (b) heating power, (c) energy confinement time, (d) DT neutron rate, and (e) electron density near the edge for two high internal inductance discharges, one with krypton puffing (solid) and one without krypton (dashed).

resulted in significantly improved $\tau_{\mathrm{E}}$ and neutron production, relative to that in similar shots without impurity gas puffing. A DT shot with $\mathrm{Kr}$ injection to maintain $\mathrm{f}_{\mathrm{r}}=70 \%$ produced $7.6 \mathrm{MJ}$ of fusion energy, a record for TFTR.

The enhanced impurity radiation was successfully combined with the technique of lithium wall conditioning $[16,17]$ to further reduce wall impurity influxes. Figure 3 illustrates the effect of puffing $\mathrm{Kr}$ into a high- $\mathrm{l}_{\mathrm{i}}$ shot (solid curve) with $32 \mathrm{MW}$ of NB heating, while continuously injecting lithium globules into the plasma edge via laser ablation ("DOLLOP" technique [17]). In the reference discharge without Kr puffing (dashed curve) a large influx of carbon and hydrogenic species (not shown) results in a large increase in edge density (e) as the energy confinement (c) and neutron rate (d) drop sharply. With $\mathrm{Kr}$ injection the confinement and neutron rate are maintained higher for a longer time before rolling over, and the edge density is maintained lower.

\section{IMPLICATIONS FOR REACTORS}

This demonstration of the successful removal of a large fraction of the heating power as radiation under reactor conditions without degrading confinement or significantly diluting the fuel ions creates the possibility of improving power handling in fusion reactors. Reduction of the power flowing to the edge may substantially ameliorate the divertor heat load problem. [1,2] The high specific radiative power of $\mathrm{Kr}$ and $\mathrm{Xe}$ at reactor temperatures permits additional radiation power of $\sim 10$ MW in TFTR with minimal fuel dilution $\left(\left|\Delta \mathrm{n}_{\mathrm{H}} / \mathrm{n}_{\mathrm{e}}\right|<10 \%, \mathrm{n}_{\mathrm{Z}} / \mathrm{n}_{\mathrm{e}} \sim 10^{-3}\right)$. The power was radiated across the entire plasma; the power profile from $\mathrm{Kr}$ was slightly hollow and that from Xe slightly peaked in the center.

Comparison of the TFTR radiated power with simulations by the MIST code [18] enabled a "calibration" of the code to provide more confidence in extending MIST modeling to reactor plasmas. For both $\mathrm{Kr}$ and $\mathrm{Xe}$ the measured radiated power profile shapes were reasonably predicted by the code with the assumptions of a diffusion rate $D(r)=1 \mathrm{~m}^{2} \mathrm{~s}^{-1}$, a radially uniform impurity concentration, and Lotz ionization rates. The total radiated power measured by bolometer arrays, however, was higher than that calculated by MIST by a factor $3.0 \pm 0.4$, where the "error" bar is strictly the statistical variation of the data. This difference suggests a deficiency in the magnitude of the radiated power cross sections of the different charge states. The required high- $Z$ impurity gas concentrations were determined from spectroscopic line intensities or from the measured increase in $Z_{\text {eff. }}$. This difference between the measured and MIST predictions is a favorable finding for modeling reactor radiative plasmas, because it means that the required high- $\mathrm{Z}$ impurity concentrations to produce a requested radiated power level are smaller by a factor of 3 than those predicted by the uncalibrated MIST. 
MIST simulations were done for production of $150 \mathrm{MW}$ of radiated power in ITER. ITER profiles having a central $\mathrm{T}_{\mathrm{e}}$ of $21 \mathrm{keV}$ and a flattish density profile with a central value of $1.33 \times$ $10^{20} \mathrm{~m}^{-3}$ were used. Other parameters were $\mathrm{R}=8.0 \mathrm{~m}$ and $\mathrm{a}=2.8 \mathrm{~m}$. For these scoping studies a circular cross section was assumed for ITER. For elongated cross sections, the radiated power should scale roughly as the plasma volume. Using the calibration factor from the TFTR data, the required concentrations of $\mathrm{Kr}$ and $\mathrm{Xe}$ were 18 and 3.9, respectively, in units of 10-5, resulting in a reduction of the hydrogenic density of $0.63 \%$ and $0.2 \%$.

\section{SUMMARY AND CONCLUSIONS}

High- $Z$ gas puffing enabled reduction of the power flowing to the edge by a factor of 3 in TFTR supershot discharges. Wall influxes were significantly reduced at high power, resulting in higher confinement times and fusion neutron production. At modest power, $\chi_{i}$ and $\chi_{\phi}$ decreased significantly. A localized increase in poloidal rotation near the edge lead to a tripling of $E_{r}$. The significance of this change in $\mathrm{E}_{\mathrm{r}}$ shear is being investigated. [19] MIST modeling, using the results from the TFTR data, suggest that nonperturbing concentrations of order $10^{-4}$ of $\mathrm{Kr}$ or $\mathrm{Xe}$ can radiatively dissipate $150 \mathrm{MW}$, which is a significant fraction of the fusion alpha heating power in ITER, and thus greatly reduce the power flowing to the divertor.

\section{REFERENCES}

[1] POST, D.E., J. Nucl. Mater. 220-222 (1995) 143.

[2] MAHDAVI, M. ALI, et al., J. Nucl. Mater. 241-243 (1997) 305., and references therein.

[3] MESSIAEN, A.M., et al., Phys. Rev. Lett. 77 (1996) 2487.

[4] GRUBER, O., et al., Phys. Rev. Lett. 72 (1995) 4217.

[5] MCGUIRE, K.M., et al., Phys. Plasmas 2 (1995) 2176.

[6] HILL, K.W., et al., submitted to Physics of Plasmas

[7] STRACHAN, J.D., et al., Phys. Rev. Lett. 58, 1004 (1987)

[8] BELL, M.G., et al., Nuclear Fusion 35 (1995) 1429.

[9] SABBAGH, S.A., et al., Plasma Physics and Controlled Nuclear Fusion Research 1996 (Proc. 16th Int. Conf., Montreal, Canada, Oct. 1996) (IAEA, Vienna, 1997) Vol. 1, 921.

[10] RAMSEY, A.T., et al., Nucl. Fusion 31 (1991) 1811.

[11] LAZARUS, E.A. et al., Nucl. Fusion 25 (1985) 135.

[12] GREENWALD, M., et al., Nucl. Fusion 28 (1988) 2199.

[13] STRACHAN, J.D. et al., J. Nucl. Mater. 196-198 (1992) 28.

[14] SYNAKOWSKI, E.J. et al., these proceedings.

[15] BELL, R.E. et al., these proceedings.

[16] MANSFIELD, D.K. et al., Phys. Plasmas 3 (1996) .

[17] MANSFIELD, D.K. et al., manuscript in preparation.

[18] HULSE, R.A., Nucl. Technol./Fusion 3 (1983) 259.

[19] ERNST, D. R. et al., these proceedings. 